\title{
Sports Ground Audience Health Monitoring System [For COVID-19] Using Smart Wireless Sensor Network
}

\author{
Dharshini $\mathrm{V}^{\mathrm{a}, 1}$, Aiswarya $\mathrm{S}^{\mathrm{a}}$, Ashwin $\mathrm{R}^{\mathrm{a}}$, Usha $\mathrm{A}^{\mathrm{b}}$ \\ ${ }^{a} U G$ Student, Department of Electronics and Communication Engineering \\ ${ }^{b}$ Associate Professor, Department of Electronics and Communication Engineering \\ Easwari Engineering College, Chennai, TN, India
}

\begin{abstract}
The recent spread of the COVID-19 has pushed us to a situation to reduce human contacts in crowded areas. The main objective of this work is to protect the audience from the spread of contagious and non-contagious diseases or infections by introducing automation in maintenance and management of sport stadiums. Taking some primary precautions such as social distancing, wearing masks, avoiding crowded areas, cleaning hands, and checking the temperature is very important. This work provides primary check-ups for the audience to pass through, to ensure that no symptomatic person is let inside the stadium. Social distancing is properly maintained using ultrasonic sensors placed inside the stadium, so that nobody sits over the sensor attached seats. To ensure the maintenance of audience data, tickets are being replaced with RFID tags and checking is done automatically through RFID readers. The information is stored and maintained automatically in the server through IoT.
\end{abstract}

Keywords. Automation, Check-up, Social distancing, Temperature

\section{Introduction}

In the last few years, we can see that healthcare has drawn a considerable amount of everyone's attention. Even during the time of widespread COVID-19 in our community, taking basic precautions are insisted to be followed. But in due time people are more likely to lead their routine lifestyle i.e., the one before COVID. Many public places were opened and there are gatherings too. So almost precautions must be taken in crowded areas to avoid the virus spread. This work tries to improve safety to prevent the spread of this virus. An automated security check-up in sports ground is introduced by which no symptomatic person is allowed inside the stadium. Here manual check-ups are avoided. Social distancing is followed by sensors implemented in-between seats. Temperature check is done to let persons inside and every individual data is stored through IoT. Various methodologies are been in usage for identifying the symptomatic person and for providing basic sanitization. Some of these methods involve humans for a check-up, where in some other places checking methods are automated.

\footnotetext{
${ }^{1}$ Dharshini V, Department of Electronics and Communication Engineering, Easwari Engineering College, TN, India; Email: dhachu.vpn@gmail.com.
} 
Basic check-up like temperature is done with digital thermometers and digital infrared thermometers. Sanitization is mostly done by using a foot-operated sanitization stand with sanitizer in it. Both of these include manpower and there exists a constant contact of the checker with every individual which results in danger for both of them. George et al. [6] proposed this to find a solution for sanitization by using contactless sanitizers. This work connects an IR sensor and a motor with the sanitizer liquid bottle so that the sensor detects humans and sprays the sanitizer liquid.

The flow of liquid is controlled using a reducer connected to the pipe and the whole setup is connected with an RC timer delay. Here, three modes of control LEDs (White, Red, and Green) are used to provide a consumer convenient setup, where White indicates the setup is in working mode and battery is in usage, Red denotes the battery is in charging mode and Green specifies that the battery is in fully charged mode. It also saves costs and power.

Chiachung Chen et al. [3] proposed that instead of digital thermometers, infrared thermometers are more convenient, fast, and easy to use. Both tympanic and forehead thermometers are used to measure the body temperature. With the spread of the coronavirus, screening of infected people is primarily done with a temperature check. By this study, the performance of two types of thermometers- tympanic infrared thermometers and an industrial infrared thermometer was evaluated. Their results were proven to be with good precision. By keeping $36{ }^{\circ} \mathrm{C}$ as standard body temperature, temperature screening is done for individuals at forehead using infrared tympanic temperature and those who screen beyond the standard temperature are possibly considered ill. Guangli Long [7] proposed a solution to find body temperature in a fast and non-contact measurement using an infrared thermometer. It converts temperature from the infrared into a voltage signal. This system comprises an operational amplifier, filter circuit, and an ADC converter. An LCD is used to display the body temperature and a voice reporter is kept to give a voice-output of the measured temperature and time. The result displays the temperature, time of acquisition and, measurement error less than $0.5{ }^{\circ} \mathrm{C}$. Md. Rezwanul Haque Khandokar et al. [4] proposed an automated way of ticketing using RFID tags in transportation industry. Uniform access is given for daily passengers and the data of passenger was updated automatically into the server each time they travel with the reader.

\section{Materials and Method}

The proposed automated monitoring system in stadium consists of two blocks, one is the entrance block and the other is the stadium block is shown in Figure 1. The sectional blocks comprise of the following components: Microcontroller, Power supply, LCD, IoT, Buzzer, RFID tag and RFID reader, Ultrasonic sensor, IR sensor, Temperature sensor, DC motor and Relay board. With these components, an automated system is created is shown in Figure 2 using Figure 1 as reference. 
ENTRANCE BLOCK

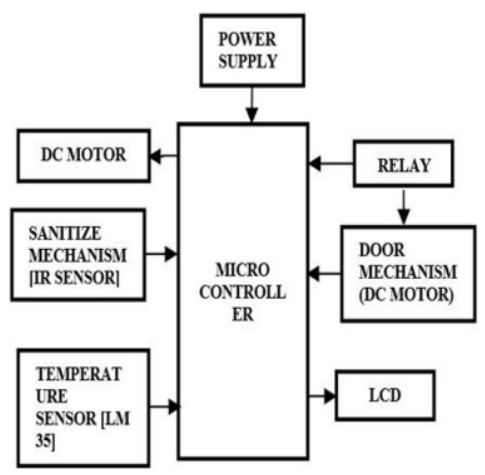

STADIUM BLOCK

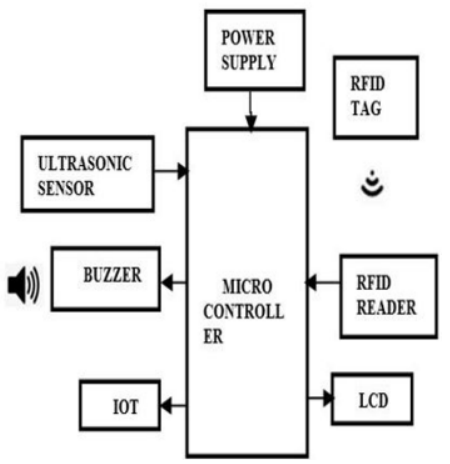

Figure 1. Block diagram of entrance block and stadium block

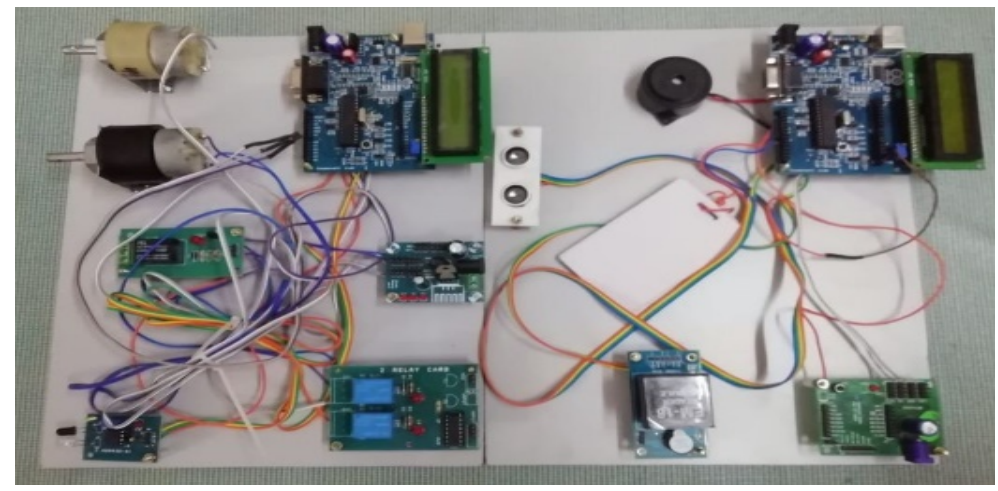

Figure 2. Hardware kit image

With respect to the block diagrams, the proposed system is mainly designed for monitoring the health condition of the audience in the sports stadium. The uppermost priority is to prevent COVID symptomatic persons from entering inside the stadium premises. This system comprises two microcontrollers and the entire block is split into two sections. In Figure 1, at entrance section the hands of each audience are sanitized using a touch-free sanitizing mechanism, i.e., using IR sensors placed at the entrance. Resistance Temperature Detectors (RTDs), a temperature sensor (LM35) is used for validating the audience's body temperature. Normal body temperature range is set over and persons exceeding that temperature range won't be allowed inside the stadium. After completion of this mandatory screening process, doors will be opened and access will be provided for the non-symptomatic audience i.e., persons with normal temperature. The audience is permitted to enter the allotted seats in the stadium section only after the verification of smart tickets using RFID tags and readers is shown in Figure 1. Individual tags are provided for the audience and they are read at the stadium entrance. The data like person's name, seat number, and ticket cost will be uploaded to the IoT server through a wireless network. Social distancing among the audience is monitored via ultrasonic sensors and intimated to the microcontroller with a buzzer sound. The main advantage of this system is that monitoring can be done remotely 
without the spread of infection and it also reduces the time consumption for checking of each individual.

\section{Results and Discussion}

Once the power supply is given, the LCD connected with the microcontroller displays the current room temperature and the obstacles detected before the IR sensor as in shown in Figure 3. In entrance block, audience are first made to undergo basic sanitization which is done with the IR sensor is shown in Figure 2. In Figure 4, When the hands are detected before the sensor at a distance of $3 \mathrm{~cm}$ and less the microcontroller displays a message with IR value as 1 . It indicates that the first hand is detected and shows a message "show_ur_hand" and the sanitizer liquid a flow is shown in Figure 5.

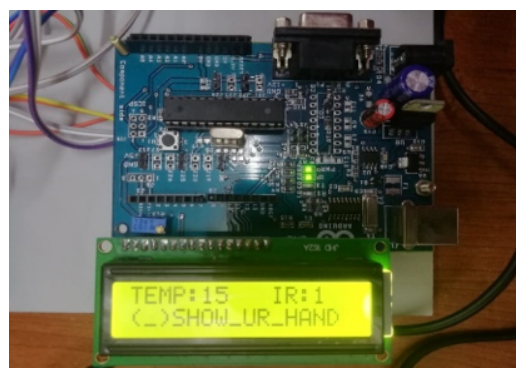

Figure 3. LCD displaying initial temperature

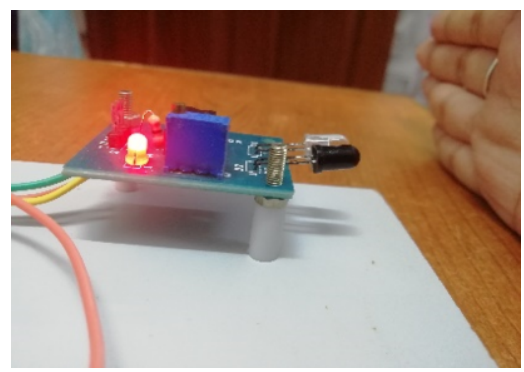

Figure 4. Hands placed over IR sensor

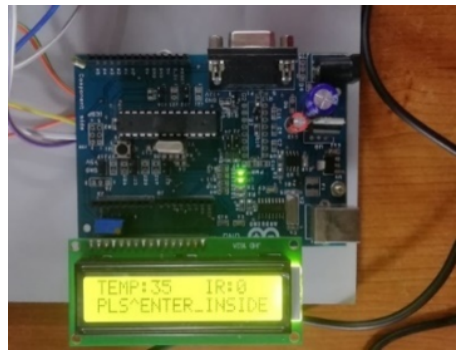

Figure 5. LCD display message

On completing the sanitization, the audience enters a temperature check-up. The normal temperature range $\left(37^{\circ} \mathrm{C}\right)$ is set in the microcontroller. It's shown in Figure 6, that prototype work, temperature is measured using LM35 sensor with a heated object and if it exceeds the normal temperature range, the microcontroller displays an output with a warning "!!!TEMP_HIGH!" and people won't be allowed inside. If the temperature measured is below the normal range, access will be given to enter inside, and the LCD displays the temperature measured and "PLS^ENTER_INSIDE" message is shown in Figure 7. On displaying this message, a dc motor will run indicating the opening and closing of doors for that person. The time taken for measuring this temperature using LM35 sensor is less than 5-7 seconds. 


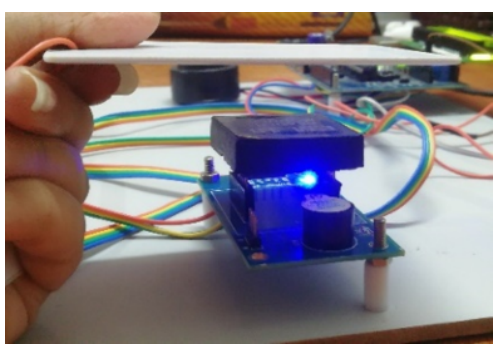

Figure 6. RFID tag above the reader

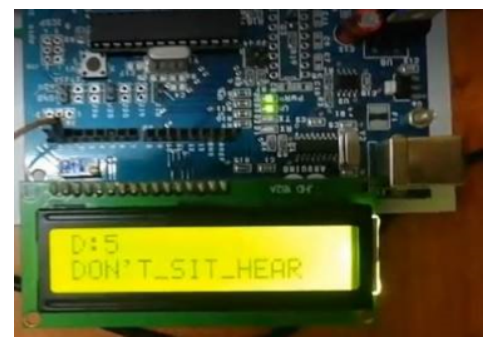

Figure 7. LCD display on obstacle Over ultrasonic sensor

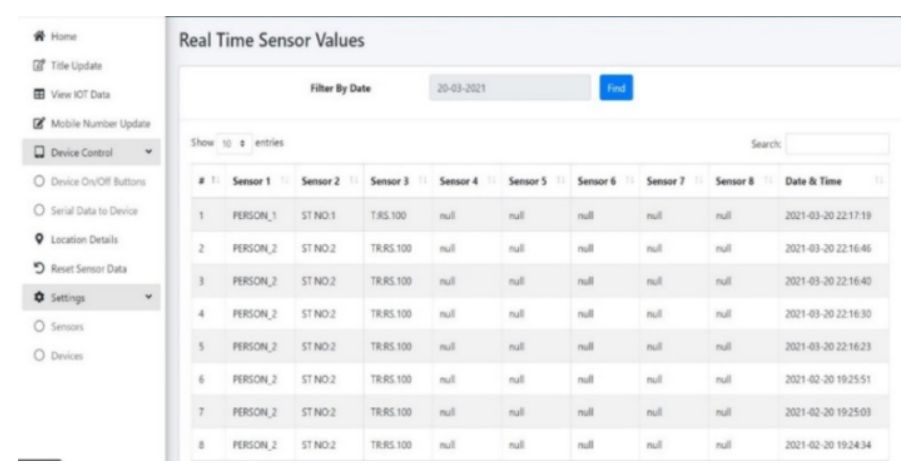

Figure 8. Data of individuals uploaded in the IoT server

All the individuals are allotted with alternate seat numbers so as to follow the basic social distancing inside the sports ground. If by mistake anyone tries to take over the non-allotted seats, a buzzer sound will arise, and the LCD displays a message saying "DON'T_SIT_HERE" is shown in Figure 8.

\section{Conclusion}

This work explores an automated check-up system in crowded areas, here in the sportsstadium. By implementing this in real life, it promotes a safer system than that involving manual check-up. It provides preliminary precaution support for the audience in the stadium by sending out audience with high temperature. The system also maintains the primary data of the audience in the IoT server and can be verified at any time. It makes them follow proper social distancing with the help of ultrasonic sensors. Thus, an automated electronic system for the prevention of virus spread while watching sports is successfully achieved. This work can be implemented in any enclosed crowded areas which also involve verification of each individual like theatres, schools etc. some additional data like entry and exit time, and measured temperature can also be made to store in the IoT server.

\section{References}

[1] Hammond, B., Ali, Y., Fendler, E., Dolan, M., \& Donovan, S. (2000). Effect of hand sanitizer use on elementary school absenteeism. American Journal of Infection Control, 28(5), 340-346. https://doi.org/10.1067/mic.2000.107276 
[2] Baslyman, M., Rezaee, R., Amyot, D., Mouttham, A., Chreyh, R., \& Geiger, G. (2014). Towards an RTLS-based Hand Hygiene Notification System. Procedia Computer Science, 37, 261-265. https://doi.org/10.1016/j.procs.2014.08.039

[3] Chen, H.-Y., Chen, A., \& Chen, C. (2020). Investigation of the Impact of Infrared Sensors on Core Body Temperature Monitoring by Comparing Measurement Sites. Sensors, 20(10), 2885. https://doi.org/10.3390/s20102885

[4] Foisal Mahedi Hasan, M., Tangim, G., Kafiul Islam, M., Rezwanul Haque Khandokar, M., \& Ul Alam, A. (2010). RFID-based ticketing for public transport system: Perspective megacity Dhaka. 2010 3rd International Conference on Computer Science and Information Technology, 459-462. https://doi.org/10.1109/ICCSIT.2010.5564067

[5] Davis, M. A., Sheng, H., Newman, J., Hancock, D. D., \& Hovde, C. J. (2006). Comparison of a waterless hand-hygiene preparation and soap-and-water hand washing to reduce coliforms on hands in animal exhibit settings. Epidemiology and Infection, 134(5), 1024-1028. https://doi.org/10.1017/ S095026880600598X

[6] Srihari, M. M. (2020). Self-Activating Sanitizer With Battery Imposed System For Cleansing Hands. 2020 Second International Conference on Inventive Research in Computing Applications (ICIRCA), 1102-1105. https://doi.org/10.1109/ICIRCA48905.2020.9183347

[7] Long, G. (2016). DESIGN OF A NON-CONTACT INFRARED THERMOMETER. International Journal on Smart Sensing and Intelligent Systems, 9(2), 1110-1129. https://doi.org/10.21307/ijssis2017-910 